\title{
Reformas educativas y redes globales para la educación Latinoamericana
}

\author{
Instituto Federal de Educação, Ciência e Tecnologia Sul-riograndense (Brasil) \\ Samuel Hilcías Carvajal Ruíz \\ Universidad Nacional Experimental Simón Rodríguez (Venezuela) \\ Arlete Ramos dos Santos \\ Universidade Estadual do Sudoeste da Bahia (Brasil)
}

\section{Resumen}

El propósito del presente artículo es reflexionar sobre documentos y estudios realizados por investigadores que discuten las relaciones público-privadas y la privatización de la educación pública en el contexto latinoamericano entre los siglos XX y XXI. En el espacio educativo, los intereses capitalistas se han consolidado a través de programas de la educación, provenientes del Banco Mundial (BM), de agencias internacionales como la Organización para la Cooperación y el Desarrollo Económico (OCDE), la Comisión Económica para América Latina y el Caribe (CEPAL), entre otros, como los sectores empresariales, principalmente, la Red Latinoamericana de Organizaciones de la Sociedad Civil para la Educación (REDUCA) constituida por organizaciones sociales de 15 países latinoamericanos, muchas de las cuales administradas por grandes empresarios que no mantienen vínculos con el área educativa estatal, sino con el sector privado, siendo la educación pública un espacio de conflicto y disputa. Palabras clave: Educación. Reformas educativas. Relaciones público-privadas. Redes globales.

\section{Reformas educativas e redes globais para a educação Latinoamericana}

\section{Resumo}

O objetivo deste artigo é refletir sobre documentos e estudos realizados por pesquisadores que discutem as relações público-privadas e a privatização da educação pública no contexto latino-americano entre os séculos XX e XXI. No espaço educacional, os interesses capitalistas foram consolidados por meio de programas educacionais, do Banco Mundial (BM), de agências internacionais como a Organização para Cooperação e Desenvolvimento Econômico (OCDE), Comissão Econômica para a América Latina e o Caribe (CEPAL), entre outros, como os setores empresariais, principalmente a Rede Latinoamericana de Organizações da Sociedade Civil para a Educação (REDUCA) - constituída por organizações sociais de 15 países da América Latina, muitas das quais são administradas por grandes empreendedores 
que não mantêm vínculos com a área educacional estadual, mas com o setor privado, sendo a educação pública um espaço de conflito e disputa.

Palavras-chave: Educação. Reformas educacionais. Relações público-privadas. Redes globais.

\section{Educational reforms and global networks for Latin american education}

\section{Abstract}

The purpose of this article is to reflect on documents and studies conducted by researchers, discussing public-private relations and the privatization of public education in the Latin American context, between the twentieth and twenty-first centuries. In the educational space, capitalist interests have been consolidated through education programs, from the World Bank (WB), from international agencies such as the Organization for Economic Cooperation and Development (OECD), the Economic Commission for Latin America and the Caribbean (ECLAC), among others, such as the business sectors, mainly the Latin American Network of Civil Society Organizations for Education (REDUCA) - constituted by social organizations from 15 Latin American countries, many of which are managed by large entrepreneurs that do not maintain links with the state educational area, but with the private sector, being public education a space of conflict and dispute.

Keywords: Education. Educational reforms. Public-private relations. Global networks.

\section{Introducción}

Constituye un hecho recurrente que cada cierto tiempo se abran debates en la sociedad respecto a la educación y sus finalidades. Esto ocurre, fundamentalmente, en coyunturas en las que algún suceso extraordinario es el centro de la opinión pública, creándose así matrices sobre la necesidad de "hacer algo" en la educación, para referirse a las necesidades educativas que debería atender la escuela. Normalmente ese "algo" que debería hacer la escuela por la sociedad, está referido a los valores, a normas, en fin, a la formación de la ciudadanía como cortafuego moral en el contexto de los valores y prácticas hegemónicas.

Por su parte, este hecho suele ser el argumento para que los gobiernos propongan reformar la educación; es decir, el sistema educativo y la organización del sistema escolar, en consecuencia, el currículo. Por tanto, pensar la educación es al mismo tiempo reflexionar críticamente sobre su praxis; es decir, convoca a plasmar lo "deseado" para superar lo "indeseado" presente 
- latente en la sociedad; de allí, expresar "las intenciones escolares explícitas" (DIAZ BARRIGA, 2006, p. 8) que no es otra cosa que la materialización del currículo.

Donald Lezere' sostenía que se debe asumir, al problematizar la educación y su expresión concreta en el currículo, como dispositivo tecnológico en las relaciones entre conocimiento y poder, un enfoque que permita explicar segundo Apple (1986) los reflejos manifiestos y latentes o codificados de los modos de producción material, valores ideológicos "[...] relaciones de clase y estructuras del poder social - tanto político - económico como racial y sexual - sobre el estado de la conciencia de la gente en una situación histórica o socio-económica precisa" (APPLE, 1986, p. 11 ).

Es decir, todo proceso dirigido a reformar la educación implica revisar los fundamentos políticos, económicos, culturales y tecno - científicos a los que ésta tributa; este proceso, también, lleva implícitamente la legitimación de ciertos conocimientos respecto a otros, que son la base de otra legitimación, la del poder.

Este hecho entraña considerar el carácter histórico de este proceso. Julia Varela recupera las categorías espacio - temporales para profundizar en la comprensión de los cambios que adquieren los procesos de socialización a través de la escuela, en este sentido sostiene que

Para entender los procesos escolares de socialización y las diferentes pedagogías es necesario tener en cuenta la configuración que en cada período histórico adoptan las relaciones sociales y, más concretamente, las relaciones de poder que inciden en la organización y definición de los saberes legítimos, así como en la formación de subjetividades específicas. [...] Categorías espaciotemporales, poder, pedagogías, saberes y sujetos constituyen dimensiones que se cruzan, se imbrican y se ramifican en el interior de las instituciones educativas (VARELA, 1992, p. 10).

De allí las complejidades generadas en torno al alcance y profundidad que reviste pensar la educación que, insistimos, significa pensar críticamente la praxis educativa. Sin embargo, esta praxis ha sido revisada en varios rincones del mundo globalizado a través de propuestas educativas que han servido de apoyo para mantener la hegemonía de la clase dominante. Dicho esto, buscamos en este texto presentar algunos estudios de autores que se han centrado su 
interés en la investigación sobre las reformas de las políticas educativas como estrategia para mantener el orden actual del capital en América Latina. De igual manera, resaltamos algunos documentos que expresan tales intereses del capitalismo globalizado, pero que tienen repercusiones específicas en cada país latinoamericano, como son los casos de la Declaración de Incheon, marco de Acción para la realización del objetivo de Desarrollo Sostenible; Documentos Oficiales Emanados de la Reunión Extraordinaria del Consejo Interamericano Económico y Social de Nivel ministerial; Proyecto de Cooperación Regional; Declaración de la Rede Latino-americana de organizaciones de la Sociedad Civil pela Educación posterior la Cúpula de las Américas, entre otros.

Para abordar los análisis respectivos, hemos dividido el texto en tres partes, que se organizan de la siguiente manera: En la primera, analizamos algunas iniciativas del gobierno de los Estados Unidos y agencias multilaterales para llevar a cabo reformas educativas en América Latina. Entendiendo que una de las estrategias utilizadas por los agentes del capital ha sido encontrar mecanismos de reinvención para mantener el bloque dominante en el poder; en la segunda parte, presentamos un estudio sobre reformas educativas dirigidas a relaciones público - privadas, cuyo supuesto ha sido principalmente 4 la consolidación de un proyecto educativo burgués, además de la mercantilización de la educación pública. Y en la última parte, analizamos la Red Latinoamericana de Organizaciones de la Sociedad Civil para la Educación (REDUCA) - formada por organizaciones sociales de quince (15) países latinoamericanos, que incluye Organizaciones No Gubernamentales - (ONG), cuyos líderes son grandes empresarios del mercado educativo, es decir, cuyos los intereses prominentes no se centran en la educación estatal.

\section{Algunas reformas educativas en América Latina}

En el ámbito político formal, este tipo de iniciativas reformistas se hace más evidente en momentos del inicio de un ciclo político - gubernamental (de gobierno), como expresión del programa de gobierno. Al mismo tiempo, estas fases reformistas abren el escenario para debatir asuntos trascendentales sobre la sociedad, sus valores (como se señala arriba), los horizontes de futuro de esa sociedad y el hecho educativo; también, develar los nudos críticos que perviven este tiempo, a saber: el trabajo y la formación para su desempeño, 
la crisis ambiental y sus impactos en la vida del planeta, la guerra y la violencia, entre otros asuntos que redundan en el ejercicio pleno de una ciudadanía responsable.

En nuestro contexto este tipo de situaciones suele tener repercusiones de significativa transcendencia, sobre todo cuando en el fondo permanece latente el debate sobre el papel del Estado y la educación, la inacabada tensión entre lo público y lo privado, que en sí mismo no es un tema menor; y por supuesto, las grandes finalidades adjudicadas a la escuela, al menos durante la modernidad, a saber: "[...] la primera, preparar al sujeto para participar e intervenir en la vida pública; y la segunda, prepararlos para la incorporación futura en el mundo del trabajo" (PEREZ GOMEZ; 2009, p. 3).

Por tanto, cuando se enfila la mirada hacia la educación se impugnan o se refrendan prácticas sociales históricamente incubadas en el seno de la sociedad. Esto pone de relieve la transcendencia del contenido del debate; de igual forma, hace visibles procedimientos $y$, de manera fundamental, a los actores protagonistas insustituible del mismo: el pueblo. Paradójicamente, la experiencia denota muchos debates sobre la educación que quedan reducidos a cenáculos de las élites políticas, económicas, culturales y académicas. Son debates vacíos de pueblo, a las espaldas de éste y, lo que es peor, generalmente las decisiones en esta materia son urdidas en contra de los intereses de las mayorías, a la que estos factores de poder afirman representar.

El contexto actual de nuestramérica, caracterizado por la tensión entre la derecha conservadora y las fuerzas democráticas populares, constituye la expresión más diáfana de una colisión de intereses en el que, la derecha, trabaja en la recomposición de la hegemonía política en la región, jalonada por las tesis ultraliberales en materia económica y con la imposición de los dogmas más retrógrados de la religión cristiana en la educación pública. Estas intenciones, en contraparte, encuentran diversas formas de resistencia político - cultural en amplios sectores de la sociedad, que abogan por la preservación del laicismo, la gratuidad y las políticas de inclusión en el ámbito de la cultura y de la educación.

Sin embargo, asistimos a un episodio más en esta confrontación que se materializa en el terreno de las ideas y la praxis educativa en la región. En este sentido, un breve repaso contextual de la evolución de las políticas públicas en educación permite enmarcar la complejidad de este proceso y dejar en 
evidencia la recurrencia conflictiva que caracteriza el campo político - ideológico de la educación, como escenario de legitimación de los saberes y del poder.

Para intentar una panorámica breve, pero a la vez que abarque un período significativo de nuestra historia contemporánea, se proponen cuatro hitos históricos que faciliten una comprensión global del asunto. El primer hito histórico lo constituye el denominado programa "Alianza para el Progreso" impulsado por el gobierno de Estados Unidos (EE.UU), presidido por John F. Kennedy, anunciado por éste el 13 de marzo de 1961. Se trata, de acuerdo con las palabras de Kennedy, de:

[...] un llamamiento a todos los pueblos del hemisferio para que nos unamos en una Alianza para el Progreso, en un vasto esfuerzo de cooperación, sin paralelo en su magnitud y en la nobleza de sus propósitos, a fin de satisfacer las necesidades fundamentales de los pueblos de América, las necesidades fundamentales de techo, trabajo y tierra, salud y escuelas (ALIANZA PARA EL PROGRESO, 1961, p. 4).

De acuerdo con lo anterior, se trató de un amplio programa político que incluía una primera dimensión de atención hacia los temas del desarrollo económico y social de la región, producto de unas economías depauperadas y una sociedad abatida por profundas asimetrías sociales y culturales, en las que prevalecía la exclusión y la pobreza. Esta política de EE.UU., es refrendada en la reunión de la Organización de Estados Americanos realizada (OEA) en Punta del Este (Uruguay), el 17 de agosto de 1961 . En la declaración final titulada: "Declaración a los Pueblos de América" y que, entre otros argumentos, sostenía que,

Esta Alianza se funda en el principio de que al amparo de la libertad y mediante las instituciones de la democracia representativa, es como mejor se satisfacen, entre otros anhelos, los de trabajo, techo y tierra, escuela y salud. No hay ni puede haber sistema que garantice verdadero progreso si no proporciona las oportunidades para que se afirme la dignidad de la persona, que es fundamento de nuestra civilización (ALIANZA PARA EL PROGRESO, 1961, p. 3).

Sin embargo, es la segunda dimensión, la geopolítica, la que determina la premura de la entonces administración Kennedy para promover una 
política integral de desarrollo hacia la región, determinada por el primer gran episodio de la Guerra fría en América, como fue el triunfo de la Revolución Cubana liderada por Fidel Castro, movimiento político revolucionario que tuvo como caldo de cultivo precisamente la situación de pobreza material y espiritual de los pueblos americanos y del Caribe.

En materia educativa, el precitado documento convocaba a "Acabar con el analfabetismo; extender, en un plazo más corto, los beneficios de la enseñanza elemental o primaria a toda persona latinoamericana y ampliar, en vasta escala, las oportunidades de educación secundaria, técnica y superior" (ALIANZA PARA EL PROGRESO, 1961, p. 5). En este marco se desarrollan los programas de alfabetización, la masificación de las enseñanzas primarias y la formación acelerada de docentes, con el propósito de incrementar la escolarización de vastos sectores sociales y con ello cimentar las bases ideológicas que permitiera el anclaje del modelo político de "democracia representativa", como expresión político - civilizatoria de la hegemonía estadounidense en la región, y los valores asociados a ésta.

El desarrollo de programas de formación de maestros dirigidos a atender las exigencias de la masificación escolar, así como la obligatoriedad de la escolarización primaria y se incrementan los programas de habilitación técnico - profesional, dirigidos a fortalecer las competencias laborales de una población con baja o escasa formación profesional, constituyen parte de un esfuerzo conjunto por introducir lo que sus promotores llamaron "los rasgos modernizadores" en la educación.

La idea fuerza que impulsa, desde la perspectiva curricular, dichas políticas se resumían en asociar las aspiraciones sociales de libertad, democracia representativa y progreso a la visión del desarrollismo capitalista periférico por entonces en boga en América Latina, como dispositivos educativos del proyecto político - ideológico de las elites en las escuelas. En este momento, la escuela es como "motor de cambio"2 y, la educación, requisito fundamental para el pretendido "ascenso social".

El triunfo de la Unidad Popular en Chile liderada por Salvador Allende en 1972, casi una década después de la implantación de la Alianza para el Progreso, constituye una evidencia más del fracaso del plan. Antes por la vía de las armas triunfa la Revolución Cubana, ahora, a través del voto, es electo el primer presidente socialista de América, el socialista Allende. 
El ejemplo chileno de legitimación por vía democrática de un modelo político antagónico al del capitalismo liberal, representa un reto para la hegemonía imperial en la región, que lo "resuelve" con el golpe de Estado contra Allende. Aquí se incuba la "Operación Cóndor"3, obra intelectual de Henry Kissinger, que permite la instauración de regímenes de fuerza y el terrorismo de Estado en el resto de los países del área, como medidas políticas para el liderazgo opositor a las políticas de los EE.UU., al mismo tiempo contener el avance de las causas populares en América del Sul.

Este proceso político que tiene como trágico desenlace la imposición de la dictadura de Augusto Pinochet en 1973 marca el segundo hito histórico de relevancia en esta breve reseña sobre la evolución de las políticas educativas en la región y las ideas que subyacen en las reformas que impulsaron, hasta hoy ancladas en el imaginario social y reforzadas en diferentes programas de gobierno.

Este momento reviste una importancia histórica notable, puesto que con la dictadura pinochetista se inaugura formalmente la era del neoliberalismo en América. Este hecho supone la implementación de un conjunto de medidas económicas de reestructuración macroestructural dirigidas fundamentalmente 8 a favorecer a los capitales extranjeros, fundamentalmente los provenientes de EE.UU. y desplazar la iniciativa pública mediante procesos de privatización de entes estratégicos del Estado chileno.

También, implica la implantación del neoliberalismo educativo como política medular dirigida al sector, en el que no sólo se copa el espacio público de escuelas privadas, sino que enfatiza en un modelo pedagógico de carácter conservador en el plano ideológico, cuyo eje ideológico es el desplazamiento de la figura del Estado como rector y garante de la educación e imponer actores particulares en ese lugar preponderante.

Caben destacar en este momento, al menos tres acontecimientos que, en el plano global y regional, tendrán repercusiones significativas, tanto en el conjunto de las políticas económicas y de desarrollo, como en las específicamente educativas, que a efectos explicativos se señalan: 1) la crisis del mercado petrolero en 1973, que se expresó en el aumento abrupto de los precios de este recurso estratégico y sus derivados; 2) este hecho derivó en una profunda crisis del Estado del Bienestar, producto del estancamiento y la recesión de la economía; y 3) El informe sobre la crisis de la democracia elaborado 
por los académicos Michel Crozier, Samuel P. Huntington y Joji Watanuki en 1975, en el que se impugnaba las "debilidades" del sistema "democrático liberal" ante las "culturas adversarias", que exigían al Estado mayor inclusión y bienestar social.

Este contexto sirve de preámbulo a la denominada crisis de la deuda externa en América Latina durante la década de los '80 y las consecuencias negativas de dicha exigencia a los Estados de la región, fundamentalmente, en las políticas sociales, entre ellas las educativas. Este periodo es conocido como la "Década perdida" 4 . En el ámbito político, se sucede la denominada "democratización" del cono sur americano con la "apertura política" que da pie a la legalización de los partidos, que luego concurrirían a comicios electorales para legitimar el modelo político representativo reconocido por mandato imperial. De esta manera se produce la transferencia del gobierno desde los poderes fácticos hacia el régimen de partidos políticos tanto tradicionales como emergentes.

Durante este tiempo se popularizan las reformas educativas de corte neoliberal, pasando de la "experiencia chilena", como teatro de ensayo, hacia el resto de los países de América Latina. Este ciclo de reformas educativas que ocupa desde finales de la década de los '80, extendiendo-se hasta las postrimerías del siglo XX, constituye, a los efectos de este ensayo, el tercer hito histórico en la evolución de las políticas públicas en educación en la región. Este proceso ocurre en el contexto de desarrollo y aplicación del Consenso de Washington; por tanto, las mencionadas reformas no se podrían explicar sin la comparecencia de agencias tales como: Banco Mundial (BM), Fondo Monetario Internacional (FMI) y Banco Interamericano de Desarrollo (BID), Organización de Estados Americanos (OEA), UNESCO-CEPAL, entre otras.

La estrategia reformista dirigida a unas sociedades abiertamente en crisis social consiste en señalar a la educación como "[...] el pilar de una estrategia de desarrollo [...]" (BRIGIER, 2002, p. 120), de la mano del informe que para tales propósitos elaboró la Comisión Económica para América Latina y El Caribe (CEPAL, 1992) titulado "Educación y conocimiento: eje de la transformación productiva con equidad". En síntesis, el mencionado documento, al tiempo que reconoce que los esfuerzos anteriores dirigidos a ampliar la cobertura de la matrícula escolar, propiciando una mayor comparecencia de niños y jóvenes a las aulas de clase, concluye que había sido "[... ] a expensas del 
deterioro la calidad de los aprendizajes, lo cual profundizaba una desigual distribución del bien educativo" (BRIGIER, 2002, p. 120).

La agenda para subsanar la situación diagnosticada apuntó hacia políticas concretas dirigidas a la descentralización del sistema escolar, la focalización y a incentivar la "autonomía en el aula". Es el momento de la disección del sistema, de gestar y aplicar políticas dirigidas a fragmentar y deslocalizar la educación, mediante operaciones técnico - pedagógicas, pero con finalidades políticas definidas, caracterizadas por: profundizar y ampliar el mercado creciente de la educación, bajo la consigna ideológica de la "sociedad educadora", un eufemismo que pretendía diluir, al menos en el sentido simbólico, y naturalizar los efectos de la privatización sobre el conjunto de la sociedad.

Los instrumentos en esta operación fueron la evaluación, el currículum nacional y el financiamiento por proyectos, como mecanismos legitimadores y que materializaron la política en la práctica cotidiana de la escuela. Estos fueron asumidos acríticamente como criterios de la "verdad", bajo el paraguas de la calidad, la eficacia y de la eficiencia. Una referencia necesaria en este asunto es que junto con estos artilugios se introduce progresivamente los llamados "currículos por competencias", expresión de la fragmentación conductista del hecho educativo, cuyas consecuencias aún siguen latentes.

Al respecto, Adriana Puiggrós (1996, p. 90) sentenciaba que "Las reformas neoliberales ahondaron los viejos problemas, produciendo un quiebre de las estructuras educacionales. Con el objetivo de disminuir la inversión y reducir las estructuras estatales, se pusieron en marcha medidas que profundizaron la inequidad y la piramidalización educativas." El cuarto y último hito corresponde a las reformas educativas ocurridas a comienzos del presente siglo. El balance de dos décadas de neoliberalismo educativo es desolador, los responsables de estos procesos reconocen

[...] una asimetría entre la inversión de recursos y los modestos resultados obtenidos. [...] en la mayoría de los países creció la presencia de la educación en la agenda políitica nacional (sanciones de nuevas leyes de educación, procesos de descentralización, políticas focalizadas y participación en pruebas internacionales), las deudas acumuladas de las reformas superan estas acciones por cuanto constatan la persistencia de la brecha educativa entre países y estratos sociales no solo expresadas en el desigualdad en el 
acceso sino también en la distribución y apropiación del conocimiento (PUIGGRÓS, 1996, p. 122).

El nuevo ciclo político que se abre en la región viene impulsado por un creciente malestar social, producto de los efectos de las políticas de corte neoliberal en amplios sectores sociales. Esto ocurre en un contexto en que el capitalismo global evidencia el protagonismo progresivo de las economías emergentes lideradas por China, que muestra unas tasas de crecimiento de su economía en torno al 10\% interanual; al mismo tiempo que crece la demanda de materias primas cuestión que tiene un impacto positivo para la mayoría de las economías suramericanas.

Tal situación constituye una base política y material que impulsa un nuevo discurso referido a las políticas sociales; éste se refleja en las acciones de la mayoría de los gobiernos electos durante este período. El énfasis de los programas de gobierno es ahora hacia la inclusión social y al combate de la pobreza. También se observa un reposicionamiento y compromiso del Estado y de la iniciativa pública en acometer tales tareas. En cuanto al ámbito educativo, se impulsan reformas legislativas dirigidas a ampliar los derechos sociales y educativos, traducidas en: ratificar el derecho a la educación, mantener gratuidad y al acceso al sistema escolar. Paralelamente, se desarrollan planes dirigidos al mantenimiento y construcción de infraestructura escolar. Todo este esfuerzo político se puede sintetizar como un proceso dirigido a expandir los derechos educativos.

\section{Reformas educativas y las redes globales: entre lo público y privado}

Al mismo tiempo que desde diversos sectores sociales se propone la búsqueda de la expansión del derecho a la educación en América Latina, defendida fundamentalmente por grupos progresistas que abogan por una educación pública de calidad e inclusiva, las organizaciones internacionales también abogan por diferentes objetivos. Por lo tanto, la educación pública, como ya se ha afirmado, es un espacio altamente disputado por diferentes grupos con diferentes puntos de vista e intereses. 
Estas agencias internacionales, centran su interés en promover el surgimiento de la agenda política, social y económica de corte neoliberal enmarcada en los intereses del capital global. Producto de esta influencia, diferentes países están reformando sus sistemas educativos, a lineándolos a los intereses del mercado a través de asociaciones, outsourcing y otros mecanismos de cooptación de lo público. Estas "asociaciones" público - privado con corporaciones nacionales y transnacionales se basan en el supuesto de que el Estado no puede resolver los problemas y retos actuales de la educación.

En el contexto histórico, político, económico y social actual, la tendencia a asociarse con instituciones corporativas y empresariales se basa en el supuesto de que los países no pueden resolver los problemas actuales. Con la adopción de la Agenda 2030 y sus Objetivos de Desarrollo Sostenible, los gobiernos han asignado un papel destacado al sector privado para lograr los nuevos objetivos y especialmente para llenar el vacío de financiación para alcanzarlos.

Las asociaciones con el sector privado son consideradas pragmáticas, orientadas hacia soluciones flexibles, eficientes y no burocráticas, atributos a menudo ausentes en proyectos y procesos puramente intergubernamenta12 les (SEITZ; MARTENS, 2017). En este sentido, el Estado y las organizaciones internacionales redefinen sus formas de acción en relación con lo público, entendiendo como necesario la aproximación con las instituciones privadas, permitiendo así alcanzar sus objetivos, retirándose como proveedores de actividad pública.

En el contexto de las propuestas globales para la educación Ball y Youdell (2008) abordan otras formas de participación del sector privado en los procesos de toma de decisiones con respecto a la política educativa, que llaman la privatización de la política, que viene ocurriendo a través de la formación de redes globales con participación especial del sector privado (BALL, 2014). Es un este contexto en el que las políticas educativas se vuelven cada vez más globales en lugar de locales o nacionales, constituyéndose parte de lo que Dale (2004) Ilama la Agenda Estructurada Globalmente para la Educación (GERM).

Debido a la importancia que reviste analizar las relaciones público-privadas y el análisis de las redes educativas en América Latina, destacamos la influencia de las redes en la educación pública (PERONI, 2015; CAETANO, 
$2016)$. Además, en este nuevo escenario en el que surgen nuevas ideas de protagonismo de la llamada sociedad civil, la participación de empresarios y nuevos filántropos se ha extendido, a medida que las redes vinculadas al sector comercial privado han crecido más allá de las fronteras. La Red Latinoamericana de Organizaciones de la Sociedad Civil para la Educación es una red compuesta por varios países latinoamericanos cuyos protagonistas son estos empresarios y filántropos, como veremos más adelante.

\section{La Reduca}

La Red Latinoamericana de Organizaciones de la Sociedad Civil para la Educación (REDUCA) está compuesta por organizaciones de quince países latinoamericanos, que trabajan para lograr un objetivo común: garantizar a todos los niños y jóvenes de la región el derecho a Educación pública inclusiva, equitativa y de calidad. Reduca entiende la educación como "[...] un hecho político, fundamental para la democracia y el desarrollo de sus países miembros, porque comparte la certeza de que el acceso de los ciudadanos a una educación de calidad" (REDUCA, 2015,s/p)

La red persigue la cooperación latinoamericana y caribeña y aborda el tema de la educación desde una perspectiva regional para estudiar, comparar prácticas y experiencias, proponer y actuar en el contexto latinoamericano. Fue lanzado con el apoyo del Banco Interamericano de Desarrollo (BID) en Brasilia, Brasil, el 16 de septiembre de 201 1, cuando los países participantes firmaron la Declaración de Brasilia, que estableció la red y sus objetivos. Cada una de las organizaciones participantes se une voluntariamente a la red sin renunciar a su identidad o agenda distintiva. Por el contrario, el trabajo de las organizaciones en sus respectivos países tiende a fortalecerse gracias al apoyo de la red. En este estudio presentamos la Red Latinoamericana de Organizaciones de la Sociedad Civil para la Educación (REDUCA), compuesta por organizaciones sociales, muchas de las cuales están dirigidas por grandes empresarios que no tienen conexiones con el área educativa estatal, sino con el sector privado. La Figura 1 y lo cuadro 1 muestra cómo se presentan las instituciones (enlaces) que participan en la red. También señalamos que Uruguay fue el último país en tener una institución comercial en la red y que, curiosamente, esta institución tiene su sede en los Estados Unidos. 


\section{Figura 1}

\section{Países miembros de Reduca y caracterización}

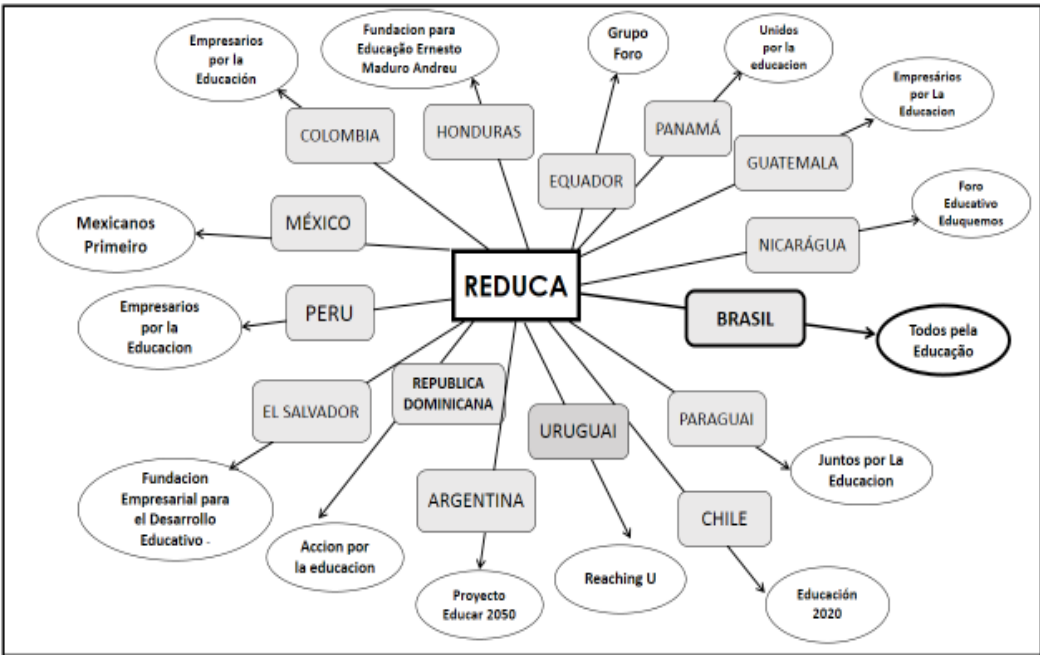

Fonte: Elaborado por Caetano com base na REDUCA. Disponível em: hitp:// www.reduca-al.net/nosotros (2019).

La gran mayoría de las instituciones que conforman REDUCA se presentan como organizaciones de la sociedad civil (ONG) y como organizaciones privadas creadas por empresarios.

\section{Quadro 1}

\section{Caracterización y composición}

\begin{tabular}{|c|c|}
\hline País & Como se Apresentam \\
\hline Brasil & $\begin{array}{c}\text { Organización no gubernamental apoyada por } \\
\text { diferentes actores de la sociedad civil. }\end{array}$ \\
\hline Argentina & $\begin{array}{c}\text { Organización no gubernamental. Participación } \\
\text { de diferentes actores de la Sociedad Civil. }\end{array}$ \\
\hline Chile & $\begin{array}{c}\text { Organización no gubernamental. Fundada con } \\
\text { participación de personas de la sociedad civil. }\end{array}$ \\
\hline Colombia & $\begin{array}{c}\text { Organización no gubernamental creada } \\
\text { y liderada por empresarios. }\end{array}$ \\
\hline El Salvador & Organización privada sin fines de lucro. \\
\hline
\end{tabular}




\section{Quadro 1}

Caracterización y composición (continuação)

\begin{tabular}{|c|c|}
\hline País & Como se Apresentam \\
\hline Honduras & $\begin{array}{l}\text { Organización sin fines de lucro, creada por un } \\
\text { empresario y su familia y por otras personas } \\
\text { del mundo empresarial y académico. }\end{array}$ \\
\hline México & $\begin{array}{l}\text { Iniciativa ciudadana, independiente y plural, creada por } \\
\text { un grupo de líderes de organizaciones civiles de corte } \\
\text { filantrópico y cultural; es una asociación civil sin fines } \\
\text { de lucro, reconocida como unidad de investigación. }\end{array}$ \\
\hline Paraguay & $\begin{array}{l}\text { Movimiento independiente, sin fines de lucro, conformado } \\
\text { por personas del sector empresarial y de la sociedad civil } \\
\text { que surge para apuntalar la educación como un factor } \\
\text { esencial para el desarrollo del país y de sus habitantes. }\end{array}$ \\
\hline Peru & $\begin{array}{l}\text { Asociación civil sin fines de lucro, formada por } \\
\text { empresarios, empresas y líderes de opinión. }\end{array}$ \\
\hline $\begin{array}{l}\text { Republica } \\
\text { Dominicana }\end{array}$ & $\begin{array}{l}\text { Organización privada sin ánimo de } \\
\text { lucro creada por empresarios. }\end{array}$ \\
\hline Equador & Centro de políticas públicas independiente, apartista y laico \\
\hline Panamá & $\begin{array}{l}\text { Organización sin fines de lucro privado, } \\
\text { creado y dirigido por los empresarios. }\end{array}$ \\
\hline Guatemala & $\begin{array}{c}\text { Organización no gubernamental creada } \\
\text { y liderada por empresarios. }\end{array}$ \\
\hline Nicarágua & $\begin{array}{l}\text { Organización privada sin fines de lucro, creada } \\
\text { por un grupo de empresarios y educadores. }\end{array}$ \\
\hline Uruguai & $\begin{array}{l}\text { Fundación que financia y co-crea programas de } \\
\text { educación de calidad para niños, niñas y adolescentes } \\
\text { en situación de vulnerabilidad en Uruguay. Nacida } \\
\text { en Estados Unidos en } 2001 \text {, ReachingU es una } \\
\text { fundación con presencia global y foco en Uruguay. }\end{array}$ \\
\hline
\end{tabular}

Fonte: REDUCA (2019) - Organizada pelos autores.

La organización del sector privado a través de filántropos tiene como objetivo definir políticas educativas, ya que existe una participación directa de estos sujetos en la definición de agendas educativas y utilizan las redes de corporaciones y organizaciones para lograr sus objetivos. "El punto de convergencia es hacer del mercado la solución obvia a los problemas sociales y económicos" (BALL, 2014, p. 59). Para el autor, las empresas están trabajando 
para cambiar la percepción pública de los problemas sociales, incluyendo la educación. La organización del sector privado está creciendo para impulsar las políticas públicas a través de las redes. Para Ball y Olmedo (2013, p. 41), crean "[...] redes [...] dentro de redes [...]. Estos son canales para la promoción de políticas y las ideas esbozadas [...] de conforman y son puestas en práctica. Peroni (2015, p. 26) advierte que "[...] las redes no son abstracciones". "Están formados y operados por sujetos individuales y colectivos en un proyecto de clase, y son parte de una ofensiva histórica del capital en este período particular del capitalismo."

La Red Latinoamericana de Organizaciones de la Sociedad Civil para la Educación (Reduca), concebida por el Banco Interamericano de Desarrollo (BID) y el movimiento Todos por la Educación (Brasil), inicialmente reunió las organizaciones de 14 países latinoamericanos que actúan para garantizar el derecho la educación inclusiva, equitativa y de calidad en la región. Actualmente hay 15 países. La Red se lanzó en Brasilia en 2011 . En ese momento, también se lanzó la Declaración de Brasilia, que habla sobre la constitución de la red. En la declaración, la red se erige como una asamblea de organizaciones de varios países latinoamericanos que tiene un compromiso 16 público común con una educación inclusiva y de calidad en los países que conforman la red. El documento también menciona que

La Rede se constituye en un ejercicio libre y voluntario para intercambiar experiencias entre los miembros, recursos y proyectos; expresar sus opiniones, proponer soluciones y acuerdos, y difundir campañas en El foro público; estudiar y evaluar medidas, programas y políticas públicas locales y regionales; sumarnos en acciones conjuntas, entre nosotros y con otros actores (REDUCA, DECLARACIÓN DE BRASILIA, 20111 .

El lanzamiento tuvo lugar en el contexto de desarrollo del Congreso Internacional, en el que se alertaba que "La educación es una agenda urgente", promovido por el "Todos por la Educación", que forma parte de la red, que contó con el apoyo del Banco Interamericano de Desarrollo como facilitador y propulsor de la iniciativa y contribuyó promoviendo la capacitación y la participación de la sociedad civil en la región de América Latina y la Unión Europea como cofinanciador. 
Estas instituciones proponen como puntos comunes, entre otros, la idea de una sociedad civil organizada, no restringida los grupos profesionales de la educación, una actuación de carácter nacional; la creencia en la educación como camino para el desarrollo del país; la defensa de la calidad de la educación, pero sin especificar los métodos pedagógicos. "Todos por la Educación" ha tratado de dialogar con los movimientos sociales para presentar sus ideas y buscar intercambiar conocimientos y aprendizajes; igualmente, destacando el intercambio de ideas con las naciones vecinas. Por ejemplo, el 2007, el movimiento brasileño publicó sus principios en Argentina, Perú, Uruguay, Panamá y Estados Unidos.

En relación con Reduca, en el que TPE se integra, las instituciones tienen una visión y misión similares. Lo que llama la atención en este caso es la búsqueda de articulación para dirigir las políticas educativas en los países miembros de la red, enfocadas especialmente hacia la educación pública. Estas instituciones utilizan la autonomía y la independencia de los gobiernos como su estrategia operativa. Érika Martins (2013), sostiene que, como novedad en el escenario latinoamericano, estas organizaciones adquieren un potencial de acción en el ámbito educativo público superior a otros segmentos de la sociedad, como los padres y los sindicatos.

Lo que llama la atención en el caso de Reduca, es el interés manifiesto de los empresarios por la educación. Erika Martins en su disertación de maestría (2013), en un acercamiento a Reduca sostiene:

Después de la formalización de la red, su coordinación estuvo bajo la responsabilidad de tres organizaciones: Todos por la Educación (Brasil), Educación 2020 (Chile) y Mexicanos Primero (México). Estos grupos son responsables de diseñar una propuesta común para la incidencia en la educación pública en todos los países que participan en la red, incluida la proyección de acciones conjuntas [...] (MARTINS, 2013, p. 113).

La propuesta inicial de acción a nivel regional se enfoca en tres frentes, a saber: el desarrollo de una plataforma de datos relevante y actualizada sobre educación en América Latina por parte del grupo mejicano; elaboración de una plataforma de información y noticias vinculada a las organizaciones de la red bajo la responsabilidad del grupo brasileño, y la construcción de un banco de buenas prácticas educativas y experiencias que puedan transferirse 
de un país a otro, bajo la responsabilidad del grupo chileno. De acuerdo con Martins (2013), estas estrategias están alineadas con las Estrategias del Banco Mundial (BM).

En 2013, la red fue seleccionada por la Unión Europea para desarrollar un proyecto conjunto con los países miembros que tratan con maestros y gerentes, primera infancia, además del Observatorio de Educación, que es la piedra angular del proyecto, e implementó un sistema de monitoreo de la educación con indicadores e información educativa que se difunde en el sitio web, titulada Observatorio Educativo. Entre otras acciones ya presentadas, Reduca se ha posicionado en varios eventos, como el documento titulado "Posicionamiento de la Red Latinoamericana de Organizaciones de la Sociedad Civil para la Educación", en el Encuentro Mundial de Educación para Todos (GEM) promovido por la UNESCO, realizado en Omán entre el 12 y 14 de mayo de 2014, que tuvo como resultado el denominado "Acuerdo de Muskat", que describe el objetivo general y los objetivos globales propuestos para la agenda educativa posterior a 2015.

Nuestros países, en corresponsabilidad entre el Estado y la sociedad, deben avanzar rápidamente para mejorar los procesos y lograr resultados de aprendizaje significativos y por toda la vida, prestando siempre atención a la equidad, el respeto por la identidad de nuestros pueblos, atención a las comunidades escolares en relación con la violencia, el desarrollo de la profesión docente, el requisito profesional correspondiente y las oportunidades de desarrollo y el reconocimiento de los docentes [...] (REDUCA, 2014).

También Reduca presentó su posición en el documento "Declaración de Reduca después de la Cumbre de las Américas 2015", con las propuestas discutidas en la $7^{a}$ Cumbre de Jefes de Estado de las Américas, celebrada en Panamá los días 10 y 11 de abril de 2015 . El documento incluye propuestas de la Red para la educación, buscando insertarse en la agenda.

Reduca insiste en que los gobiernos y la OEA cumplan su propósito de 'crear, sin restricción o limitación de participación, el Foro Interamericano sobre la Sociedad Civil y los Actores Sociales, para que haya un proceso continuo de participación y consulta con la sociedad civil. y actores sociales, y no solo antes y en el momento de la Cumbre de las Américas', como una forma efectiva para que 
los ciudadanos participen en los procesos de la Cumbre (REDUCA, 2015).

En la actualidad, Reduca, en asociación con la Fundación Sura, publicó un estudio titulado "Aprender es más". La red también hizo una declaración señalando cinco desafíos en la región, que están estrechamente relacionados con los Objetivos de Desarrollo Sostenible, cuyo cumplimiento sigue siendo un desafío para América Latina, en correspondencia con organizaciones internacionales tales como el Banco Mundial, la OEA-Organización de Estados Iberoamericanos y el Banco Interamericano de Desarrollo (BID). El Manifiesto de Reduca contiene 5 objetivos: garantizar trayectorias completas, garantizar el aprendizaje con sentido, potenciar el rol de docentes y directivos, sumar esfuerzos por medio de alianzas e ir más allá de las pruebas estandarizadas (REDUCA, 2015).

La Reduca presentó \#ManifiestoREDUCA y exigió que los gobiernos tomen medidas pronto para asegurar los objetivos. Es decir, la red actúa políticamente conquistando y ocupando espacios en eventos públicos, gubernamentales, entre otros.

En este sentido, Reduca, mientras defiende la educación como una prioridad en América Latina, desarrolla acciones que están estrechamente relacionadas con los Objetivos de Desarrollo Sostenible, cuyo cumplimiento sigue siendo un desafío para América Latina, que no compartimos. La cuestión clave es que al delegar o compartir responsabilidades con empresarios y filántropos, los países renuncian a lo que les es más preciado: la autonomía para construir políticas públicas verdaderamente democráticas, con una gestión democrática y centrada en el proceso educativo destinado a formar ciudadanos libres, autónomos.

Ahora bien, destaca en los intereses de empresarios y filántropos que financian estas redes es su compromiso con metas y resultados materiales, además de insertar propuestas gerenciales que modifiquen la cultura de la educación pública, alineándolas con la doctrina del mercado. 


\section{Consideraciones}

En este texto buscamos presentar brevemente la educación como un territorio de disputas en el contexto latinoamericano, destacando algunas acciones implementadas en los siglos XX y XXI. Si bien reconocemos la importancia de los movimientos sociales y los sindicatos de la clase trabajadora en la implementación de una propuesta educativa contrahegemónica en la región, utilizamos para nuestro análisis sólo las influencias y estrategias organizadas por los heraldos del capital, que se han organizado en torno a un Proyecto de educación hegemónica, que en las últimas décadas de los siglos XX y XXI se ha materializado a través de la agenda liberal, pero con confrontaciones entre sectores progresistas y conservadores.

Por tanto, hacemos hincapié en que, en algunos países latinoamericanos, los intereses conservadores ya están avanzando a través de los sectores de ultraderecha, con propuestas educativas cada vez más centradas en la consolidación del proyecto de globalización y neoliberalismo del capitalismo globalizado, representado por las siguientes agencias internacionales: $O C D E$, CEPAL, BM, BIRF, BID, entre otros.

20 Demostramos en el texto a través del análisis de algunos documentos que la ofensiva capitalista con el objetivo de garantizar su proyecto histórico de sociedad ha estado actuando en cada país latinoamericano de manera estratégica, concentrando sus acciones en la última década del siglo XXI, en acciones de alianzas público-privadas y privatización de la educación pública.

Es con este propósito que Reduca opera, no solo en las instituciones de sus países miembros, sino también a nivel macro, como la Cumbre de las Américas y la Reunión Mundial de Educación para Todos. Es importante tener en cuenta que esta red se hace llamar como perteneciente a la sociedad civil; sin embargo, básicamente está formada por empresarios con opiniones hegemónicas sobre educación, sociedad y, sobre todo, sobre el concepto de democracia, que es cuestionable. Asimismo, utilizan estrategias de creación de consenso, el establecimiento de relaciones entre empresas y buscan la adhesión de la población a su proyecto político y económico. Es decir, definitivamente tenemos distintos proyectos en disputa en educación y las redes empresariales demuestran su fortaleza financiera invirtiendo grandes sumas en resolver problemas históricos complejos, expandiendo el sector privado, reforzando la 
idea de que el capitalismo no es la causa sino La solución a los problemas del mundo.

\section{Notas}

1 Citado por Apple (1986)

2 Claudio Suásnabar (2017, p. 118).

3 De acuerdo con Marcos Ferreira Navarro (2014, p. 153), la Operación Cóndor "[...] debe ser entendida como una organización paramilitar de carácter secreto, encargada de eliminar a elementos de oposición, garantizar el establecimiento en el poder a los nuevos ejecutivos militares de varios países latino-americanos y evitar una organización políitica, económica y social por parte de las clases populares".

4 Pedro Brigier (2002, p. 341 ) afirma: "Los años '80 se caracterizaron por el estancamiento económico, la carga agobiadora de una deuda que limitaba el acceso a los mercados financieros internacionales, una reducción del 9\% del ingreso per cápita entre 1980 y 1990, y la inflación que sobrepasó en algunos países al 1.000\%."

5 Disponível em: Somos Reduca. https://www.reduca-al.net/nosotros

\section{Referencias}

ALIANZA PARA EL PROGRESO. Organización de los Estados Americanos. Documentos Oficiales Emanados de la Reunión Extraordinaria del Consejo Interamericano Económico y Social al Nivel Ministerial. Punta del Este: (Uruguay), 1961.

APPLE, Michael. Ideología y currículo. Madrid: Ediciones Akal, 1986.

BALL. Stephen. Educação Global S.A. Novas redes políticas e o imaginário neoliberal. Ponta Grossa: UEPG, 2014.

BALL. Stephen; YOUDELL. D. Hidden Privatisation in Public Education. Institute of Education/ University of London, Bruxelas, 2008. Disponivel em: http://www.campaignforeducation. org/docs/privatisation/Endogenous\%2OPrivatization\%20Stephen\%2OBall_ENGLISH.pdf. Acesso em: 30 jan. 2015.

BALL, Stephen; OLMEDO, Antonio. A Nova Filantropia, o Capitalismo Social e as Redes de Políticas Globais em Educação. In: PERONI, Vera Maria Vidal (org.). Redefinições das fronteiras entre o público e o privado: implicações para a democratização da educação. Brasília: Líber Livro, 2013. 
BRIEGER, Pedro. De la década perdida a la década del mito neoliberal. En Gambina, J. La globalización económico financiera. Su impacto en América Latina. Buenos Aires: CLACSO, 2002.

CAETANO.M.R. Redes globais e educação: A Rede Latino Americana da sociedade civil para a educação-REDUCA. Cadernos ANPAE, v. 41, 2016.

CEPAL. Comisión Económica para América Latina y el Caribe. Educación y conocimiento: eje de la transformación productiva con equidad. Santiago de Chile: CEPAL-UNESCO, 1992.

DECLARACIÓN DE INCHEON. Marco de Acción para la realización del Objetivo De Desarrollo Sostenible. Garantizar una educación inclusiva y equitativa de calidad y promover oportunidades de aprendizaje permanente para todos. Organización de las Naciones Unidas para la Educación, la Ciencia y la Cultura. Disponivel em: https://unesdoc.unesco. org/ark:/48223/pf0000245656_spa. Acesso em: $1^{\circ}$ fev. 2020.

DÍAZ BARRIGA, Ángel. La educación en valores: avatares del currículum formal, oculto y los temas transversales. Revista Electrónica de Investigación Educativa, v. 8, n. 1, 2006. Disponivel em: http://redie.uabc.mx/vol8nol/contenido-diazbarriga2.html. Acesso em: 24 jul. 2019.

22 NAVARRO, Marcos Ferreira. Operación cóndor: antecedentes, formación y acciones. Ab Initio, v. 9, 2014.

MARTINS. Erika Moreira. Movimento "Todos pela Educação": um projeto de nação para a educação brasileira. 2013. Dissertação (Mestrado em Educação) - Programa de PósGraduação em Educação, Universidade Estadual de Campinas, Campinas, 2013.

PÉREZ GÓMEZ, Ángel. Las funciones sociales de la escuela: de la reproducción a la reconstrucción crítica del conocimiento y la experiencia. Buenos Aires: Laboratório de Políticas Públicas - CLACSO, 2009. Disponivel em: hitp://bibliotecavirtual.clacso.org.ar/ Argentina/lpp/20100324022908/9.pdf. Acesso em: 20 maio 2020.

PERONI, Vera Maria Vidal (org.). Implicações da relação público-privada para a democratização da educação no Brasil. In: PERONI, Vera Maria Vidal (org.). Diálogos sobre as redefinições do papel do Estado e sobre as fronteiras entre o público e o privado. São Leopoldo: Oikos, 2015.

PUIGGRÓS, Adriana. Educación neoliberal y quiebre educativo. Revista Nueva Sociedad, n. 146, nov-dic., p. 90-101, 1996. 
REDUCA. Rede Latino-americana de Organizações da Sociedade Civil para a Educação: Declaração de Brasília, 2011. Disponível em: http://www.reducaal.net/narrativa_red/ archivos/DeclaraciondeBrasilia.pdfAcesso em: 10 fev. 2019.

REDUCA. Posicionamento da Rede Latino-Americana de Organizações da Sociedade Civil pela Educação no Encontro Mundial Educação para Todos (GEM), 2014. Disponível em: https://issuu.com/camilopinto/docs/posicionamento_reduca_reuniao_unes Acesso em: 10 fev. 2016.

REDUCA. Declaração da Rede Latino-americana de organizações da Sociedade Civil pela Educação posterior a Cúpula das Américas, 2015. Disponível em: http://www. todospelaeducacao.org. br/biblioteca/ $1506 /$ declaracao-da-reduca-posterior-a-cupula-das-americas-2015. Acesso em: 9 fev. 2019.

SEITZ, Karolin; MARTENS, Jens. Philanthrolateralism: Private Funding and Corporate Influence in the United Nations, 2017. Disponivel em: https://www.researchgate.net/ publication/319397729_Philanthrolateralism_Private_Funding_and_Corporate_Influence_ in_the_United_Nations. Acesso em: 10 jan. 2020.

SUÁSNABAR, Claudio. Los ciclos de reforma educativa en América Latina: 1960, 1990 y 2000. Revista Española de Educación Comparada, n. 30, jul./dic. 2017.

TODOS PELA EDUCAÇÃO. Observatório online traz dados educacionais da América

Latina, 18 ago. 2015. Disponível em: http://www.todospelaeducacao.org.br/reportagens-tpe/34787/observatorio-online-traz-dados-educacionais-da-america-latina. Acesso em: 9 fev. 2019.

VARELA, Julia. Categorías espacio - temporales y social acción escolar: del individualismo al narcisismo. Revista de Educación, n. 298, 1992. Disponivel em: http://www.educacionyfp. gob.es/dam/jcr:67470c3 1-6999-4b0e-8a4d-ed483ceb652b/re2980100486-pdf. Acesso em: 20 fev. 2020. 
Profa. Dra. Maria Raquel Caetano Instituto Federal de Educação, Ciência e Tecnologia Sul-riograndense (Brasil) Mestrado ProfEPT e docente do IFSUL - Campus Sapucaia do Sul Grupo de Pesquisa sobre relações público-privado na Educação integra a Rede Latino-Americana e Africana de Pesquisadores em Privatização da Educação (ReLAAPPe) Orcid id: https: / / orcid.org/0000-000 1-6973-908X E-mail: caetanoraquel2013@gmail.com

Prof. Dr. Samuel Hilcías Carvajal Ruíz Universidad Nacional Experimental Simón Rodríguez (UNESR) Orcid id: https: / / orcid.org/0000-0003-0747-296X E-mail: shcarvajal@gmail.com

Profa. Dra. Arlete Ramos dos Santos Universidade Estadual do Sudoeste da Bahia (UESB) Líder do Grupo de Estudos Movimentos Sociais, Diversidade e Educação do Campo (GEPEMDEC/CNPq) Orcid id: https:/ / orcid.org/0000-0003-02 17-3805 E-mail: arlerp@hotmail.com Recebido $1^{\circ}$ jul. 2020 Aceito 15 jul. 2020 